\title{
NUMERICAL ANALYSIS OF SIGNAL GAIN AND NOISE FIGURE OF S-BAND Tm-DOPED W-TYPE FIBRE AMPLIFIER WITH DIFFERENT PUMPING CONFIGURATIONS
}

\author{
M.A. Khodasevich, S.A. Koval, and G.V. Sinitsyn \\ B.I. Stepanov Institute of Physics, National Academy of Sciences of Belarus, Nezalezhnasti Ave. 68, 220072 Minsk, Belarus \\ E-mail: m.khodasevich@ifanbel.bas-net.by
}

Received 13 October 2009; revised 15 February 2010; accepted 19 March 2010

\begin{abstract}
A completely spectrally and spatially resolved theoretical model of a silica-host thulium-doped fibre amplifier is presented. In contrast to the models reported so far, multimodal structure of emission is taken into account. Several promising pumping schemes are considered. Genetic algorithm is implemented for pumping scheme optimization to attain the maximum gain or minimum gain ripple. W-type and step-index fibre performance is compared. The results obtained allow to select the best parameters for each considered scheme.
\end{abstract}

Keywords: thulium-doped fibre amplifier, W-type fibre, genetic algorithm

PACS: $42.81 .-\mathrm{i}$, 42.55.Wd, 42.81.Wg

\section{Introduction}

Continuously increasing demand for capacity in the telecommunication systems stimulates investigations on the optical bandwidth expansion. Current longhaul transmission systems utilize erbium doped fibre amplifiers (EDFAs) that operate in the C- and Lbands (1530-1565 and 1565-1625 nm, respectively) and multi-pumped fibre Raman amplifiers with bandwidth up to $100 \mathrm{~nm}$. The $\mathrm{C}$ - and L-bands represent only a small portion of the low-loss spectral region available in standard single-mode fibres $(1440-1650 \mathrm{~nm})$ or fibres with low $\mathrm{OH}$ absorption (1360-1660 nm). The next spectral expansion following the $\mathrm{C}$ - and $\mathrm{L}$-bands is the S-band (1460-1530 nm). Among the most promising candidates for optical amplification in this spectral region are the thulium-doped fibre amplifiers (TDFAs).

Stimulated emission in $\mathrm{Tm}^{3+}$ ions at wavelengths around $1470 \mathrm{~nm}$ occurs between ${ }^{3} \mathrm{H}_{4}$ and ${ }^{3} \mathrm{~F}_{4}$ energy levels. Two main problems complicate the use of this transition.

Firstly, $\mathrm{Tm}^{3+}$ behaves as a four-level laser system, where the lifetime of the upper laser level is shorter than that of the lower one. This problem can be solved by using different up-conversion schemes of pumping at 800, 1064, 1410, and $1560 \mathrm{~nm}$ (see Fig. 1) [1-5].

The second problem is possible non-radiative decay of ${ }^{3} \mathrm{H}_{4}$ level via intermediate ${ }^{3} \mathrm{H}_{5}$ level, which has

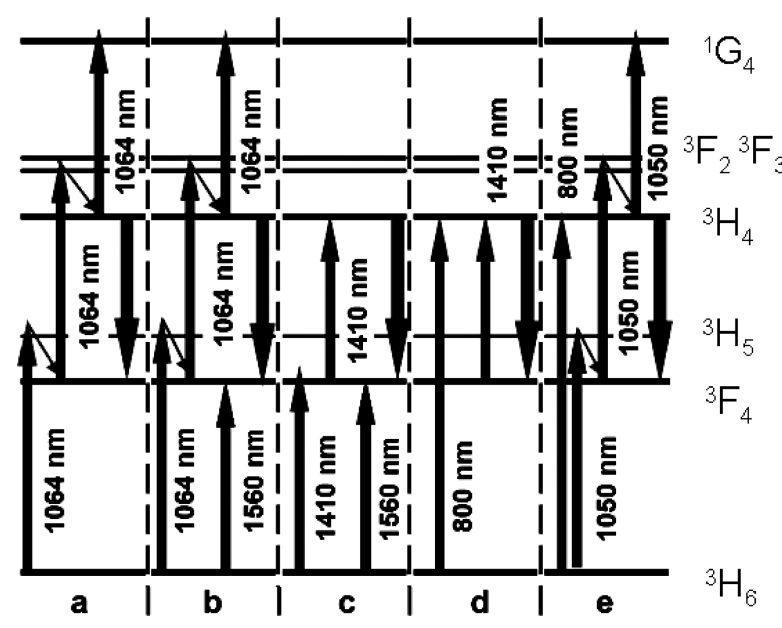

Fig. 1. Several TDFA pumping schemes, reported so far.

large probability, especially in the conventional silica fibre host. Therefore most of TDFAs are based on low phonon energy fibre materials, for example fluoride composites. However, the usage of non-silica materials results in problems with fabrication, exploitation, and splicing to the standard telecommunication fibre.

Complicated energy level diagram and the impossibility of obtaining analytical results under any reasonable assumptions are the reasons why only few TDFA models are reported up to this date in contrast to the comprehensively studied EDFAs. Among the models developed one can emphasize the model by Peterka 
et al. [6]. However, all the existing models have the disadvantage of disregarding the mode structure of emission in wide wavelength range that is characteristic of TDFA. Actually, amplified spontaneous emission (ASE) is generated in TDFA in 400-2200 nm spectral range, shorter wavelength limit of which corresponds to 3-9 modes under ordinary step-index fibre parameters.

Wideband ASE impairs amplifier characteristics by deteriorating noise performance and lowering pump conversion efficiency. One of the possible solutions for solving the ASE problem is the usage of W-type fibre $[7,8]$. In contrast to ordinary step-index fibre the Wfibre has the fundamental mode cut-off and thus can be considered as a short wavelength pass filter [9]. W-fibre can be designed to effectively filter out the radiation in competing long-wavelength band of TDFA (above $\sim 1500 \mathrm{~nm}$ ) and support single mode operation in all wavelength region of interest at the same time. In this paper we present theoretical analysis of possible Wtype fibre utilization benefits in the case of silica-host TDFA.

\section{Theoretical model}

We consider here an S-band thulium-doped silica fibre amplifier. The following assumptions are implemented:

- cooperative effects are neglected $\left(\mathrm{Tm}^{3+}\right.$ concentration is relatively low, $1.5 \cdot 10^{-19} \mathrm{~cm}^{-3}$ ),

- homogeneously broadened thulium spectra,

- W-type fibre,

- monochromatic multi-wavelength pumping,

- wavelength-division multiplexed (WDM) signals,

- wide-band ASE.

Our model is based on the ordinary rate and propagation equations. They are presented for four levels, as the non-radiative decay rates from ${ }^{3} \mathrm{~F}_{2},{ }^{3} \mathrm{~F}_{3}$, and ${ }^{3} \mathrm{H}_{5}$ levels to the respective underlying levels are high $\left(\gg 10^{5} \mathrm{~s}^{-1}\right)$, so the corresponding populations can be neglected.

Usually rate equations are written for average level populations at a certain longitudinal coordinate, which implies the coincidence of transverse profiles of $\mathrm{Tm}^{3+}$ concentration and each level population density. We do not use this assumption, thus all items in the rate equations are considered to be local (i.e. correspond to a certain point of the fibre, and the cylindrical coordinate system with $z$ axis coinciding with the longitudinal fibre axis is used):

$$
\begin{aligned}
& \frac{\mathrm{d} N_{1}}{\mathrm{~d} t}=N_{0}\left(W_{01}+W_{02}\right)-N_{1}\left(W_{10}+W_{13}+W_{14}\right. \\
& \left.+A_{1}^{\mathrm{nr}}+A_{10}^{\mathrm{r}}\right)+N_{3}\left(W_{31}+W_{32}+A_{3}^{\mathrm{nr}}+A_{32}^{\mathrm{r}}+A_{31}^{\mathrm{r}}\right) \\
& +N_{5}\left(A_{51}^{\mathrm{r}}+A_{52}^{\mathrm{r}}\right), \\
& \frac{\mathrm{d} N_{3}}{\mathrm{~d} t}=N_{0} W_{03}+N_{1}\left(W_{13}+W_{14}\right) \\
& -N_{3}\left(W_{35}+W_{32}+W_{31}+W_{30}+A_{3}^{\mathrm{nr}}+\sum_{j=0}^{2} A_{3 j}^{\mathrm{r}}\right) \\
& +N_{5}\left(A_{5}^{\mathrm{nr}}+A_{54}^{\mathrm{r}}+A_{53}^{\mathrm{r}}\right), \\
& \frac{\mathrm{d} N_{5}}{\mathrm{~d} t}=N_{0} W_{05}+N_{3} W_{35} \\
& -N_{5}\left(W_{50}+A_{5}^{\mathrm{nr}}+\sum_{j=0}^{4} A_{5 j}^{\mathrm{r}}\right), \\
& N_{\mathrm{t}}=N_{0}+N_{1}+N_{3}+N_{5},
\end{aligned}
$$

where $N_{i}=N_{i}(r, \phi, z)$ is the $i$ th level population density, $N_{\mathrm{t}}$ is $\mathrm{Tm}^{3+}$ ion concentration, $W_{i j}=W_{i j}(r, \phi, z)$ are stimulated emission / absorption rates, $A_{i j}^{\mathrm{r}}$ and $A_{i}^{\mathrm{nr}}$ denote radiative and nonradiative spontaneous relaxation rates respectively.

$W_{i j}$ expression that takes into account mode structure of emission has the following form:

$$
\begin{aligned}
& W_{i j}(r, \phi, z)=\int_{\lambda=0}^{\infty} \mathrm{d} \lambda \frac{\sigma_{i j}(\lambda) \lambda}{h c} \\
& \times \sum_{m}\left[P_{m}^{+}(z, \lambda)+P_{m}^{-}(z, \lambda)\right] \overline{\psi_{m}(r, \phi, \lambda)},
\end{aligned}
$$

where $\sigma_{i j}(\lambda)$ is the respective transition cross-section, $P_{m}^{+}(z, \lambda)$ and $P_{m}^{-}(z, \lambda)$ are emission powers, propagating in forward (signal codirectional) and backward directions respectively, $m$ is the index of emission modes, $\overline{\psi_{m}(r, \phi, \lambda)}$ is a normalized mode envelope $\left(\int \overline{\psi_{m}(r, \phi, \lambda)} r \mathrm{~d} r \mathrm{~d} \phi=1\right)$.

Explicit expressions for $N_{i}$ obtained from (1)-(5) under stationary conditions are omitted here because of their excessive size.

System of propagation equations includes expressions for WDM signals, forward/backward pumps, 
and forward / backward ASE. Full set of expressions is rather extensive, so only one equation of each type is listed (each equation refers to a separate mode $m, b$ is doping radius).

Signal:

$$
\begin{aligned}
& \frac{\mathrm{d} P_{\mathrm{s} m}(\lambda, z)}{\mathrm{d} z}=P_{\mathrm{s} m}(\lambda, z) \int_{0}^{b} \int_{0}^{2 \pi}\left[\sigma_{31}(\lambda) N_{3}(r, \phi, z)\right. \\
& \left.-\sigma_{13}(\lambda) N_{1}(r, \phi, z)-\sigma_{01}(\lambda) N_{0}(r, \phi, z)\right] \\
& \times \overline{\psi_{\mathrm{s} m}(r, \phi, \lambda)} r \mathrm{~d} r \mathrm{~d} \phi .
\end{aligned}
$$

Pump power at $1064 \mathrm{~nm}$ :

$$
\begin{aligned}
& \frac{\mathrm{d} P_{\mathrm{p} m}^{+}(\lambda, z)}{\mathrm{d} z}=-P_{\mathrm{p} m}^{+}(\lambda, z) \int_{0}^{b} \int_{0}^{2 \pi}\left[\sigma_{02}(\lambda) N_{0}(r, \phi, z)\right. \\
& \left.+\sigma_{14}(\lambda) N_{1}(r, \phi, z)+\sigma_{35}(\lambda) N_{3}(r, \phi, z)\right] \\
& \times \overline{\psi_{\mathrm{p} m}(r, \phi, \lambda)} r \mathrm{~d} r \mathrm{~d} \phi .
\end{aligned}
$$

ASE in $800 \mathrm{~nm}$ spectral region:

$$
\begin{aligned}
& \frac{\mathrm{d} P_{\mathrm{ASE} m}^{+}(\lambda, z)}{\mathrm{d} z}=P_{\mathrm{ASE} m}^{+}(\lambda, z) \\
& \times \int_{0}^{b} \int_{0}^{2 \pi}\left[\sigma_{30}(\lambda) N_{3}(r, \phi, z)-\sigma_{03}(\lambda) N_{0}(r, \phi, z)\right] \\
& \times \overline{\psi_{\mathrm{ASE} m}(r, \phi, \lambda)} r \mathrm{~d} r \mathrm{~d} \phi+2 \frac{h c^{2}}{\lambda^{3}} \sigma_{30}(\lambda) \\
& \times \int_{0}^{b} \int_{0}^{2 \pi} N_{3}(r, \phi, z) \overline{\psi_{\mathrm{ASE} m}(r, \phi, \lambda)} r \mathrm{~d} r \mathrm{~d} \phi
\end{aligned}
$$

Propagation equations' system is solved numerically using iterative double-direction integration chain. As all the equations are local, two integrations must be performed: transverse one to obtain the total power increment at certain fibre section and longitudinal one to derive the emission propagation dynamics [10].

The following fibre parameters were chosen for numerical modelling: W-type fibre with $2.6 \mu \mathrm{m}$ core diameter, core refraction index of 1.5 , inner cladding/ core refraction ratio 0.99 , outer cladding/core refraction ratio 0.995 , core radius/inner cladding thickness ratio of 0.27 . This fibre is single-mode for wavelengths longer than $420 \mathrm{~nm}$ and has a fundamental mode cut-



Fig. 2. Dependence of TDFA gain spectrum $G$ over amplifier length $L$. Single pump at $1064 \mathrm{~nm}$ is used.

off at $1590 \mathrm{~nm}$, allowing pumping schemes presented in Fig. 1 and filtering ASE from the both laser levels to the appropriate underlying levels $\left({ }^{3} \mathrm{H}_{4} \rightarrow{ }^{3} \mathrm{H}_{5}\right.$ and $\left.{ }^{3} \mathrm{~F}_{4} \rightarrow{ }^{3} \mathrm{H}_{6}\right)$. An example of the results obtained is shown in Fig. 2.

W-type fibre amplifier performance is compared with that of single-mode step-index fibre amplifier with the same core parameters and numerical aperture of 0.3 .

\section{Genetic algorithm application for TDFA pumping scheme optimization}

Pumping schemes' optimization is carried out to obtain the maximum gain or the minimum gain ripple of TDFA in 1450-1500 nm spectral range near the gain maximum $(1470 \mathrm{~nm})$. We use here the genetic algorithm (GA) method that has proven its effectiveness in a wide range of problems where direct analytical methods are not applicable. GA can be briefly characterised as a heuristic search algorithm, utilized for the solution of optimization and modelling problems by consistent selection, combination, and variation of the sought parameters with the use of mechanisms, similar to the biological evolution [11]. GA is stochastic by its nature and is dependent neither on initial conditions nor on the search space properties. Generally GA as an optimization method is more effective than Monte-Carlo methods or direct search space screening [12].

The following algorithm features have been chosen on the basis of the previous investigation [13]:

- fixed population size of 50 persons,

- 8 bit parameter coding, 


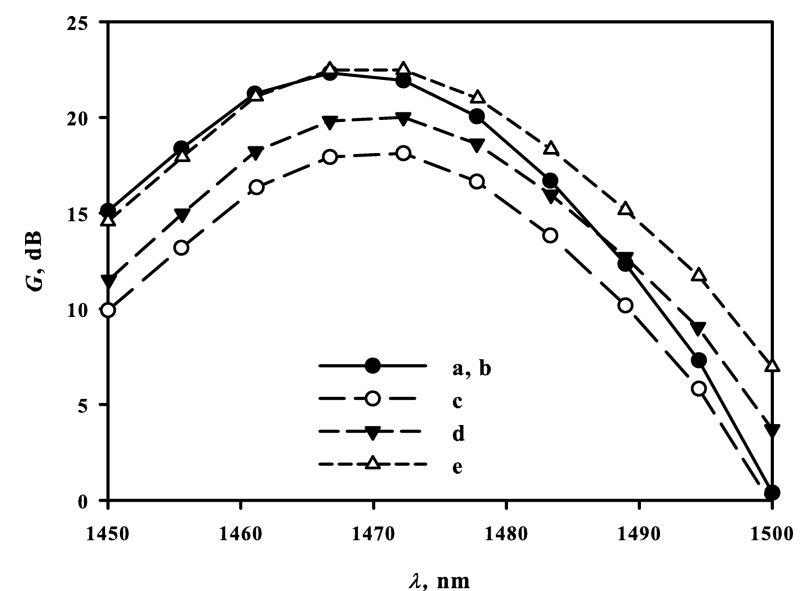

Fig. 3. Maximum gain spectra for the considered TDFA pumping schemes labeled according to Fig. 1.

- multipoint crossover operator with the number of break points equal to the parameter quantity,

- crossover probability of $60 \%$,

- uniform mutation operator with $95 \%$ probability of at least one bit inversion,

- 3 ranked tournament as the selection method,

- elitism -2 individuals with the maximal fitness are preserved for the next generation.

There is no consistent and strict mathematical GA theory these days, so these features were mainly determined as the result of numerical experiments.

Pumping schemes' optimization was carried out for the schemes in Fig. 1 under the following assumptions:

- maximal gain or minimal gain ripple as the sought parameter,

- pump wavelengths and forward/backward pump powers' ratio as the variable parameters (both possible pumping directions are taken into account),

- pump wavelengths are varied within the respective transition absorption band,

- total pump power of $1 \mathrm{~W}$, signal power of $10 \mu \mathrm{W}$,

- spectrum flattening is carried out in 1450-1500 nm range around the gain maximum $(1470 \mathrm{~nm})$,

- the ratio of the average gain to the gain unevenness over the considered spectral region as the gain ripple criterion.

The results of pump powers' and wavelengths' optimization are shown in Figs. 3, 4. Corresponding optimal pumping parameters are listed in Tables 1, 2 . Pumping schemes are labeled according to Fig. 1. Figure 5 shows noise figure spectra for the gain-optimal TDFA pumping schemes. One can see that for both

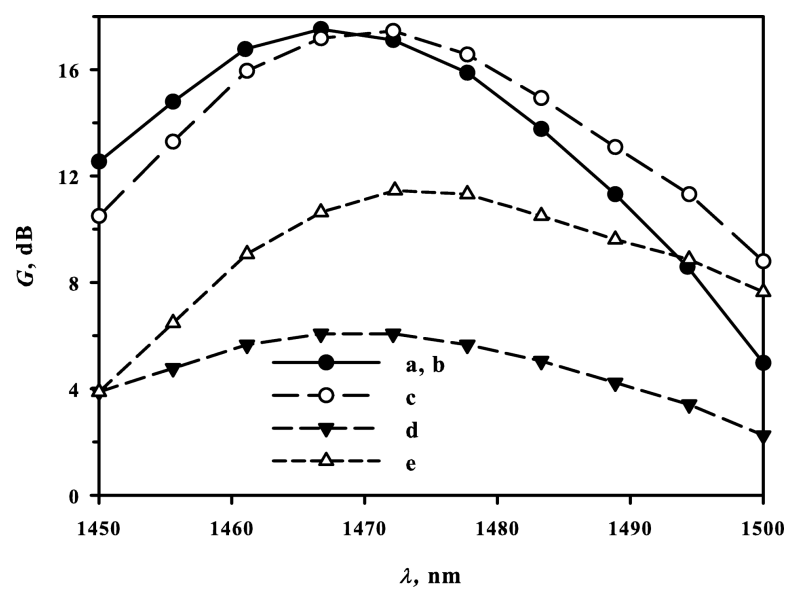

Fig. 4. Minimum gain ripple spectra for the considered TDFA pumping schemes labeled according to Fig. 1.



Fig. 5. Noise figure spectra for the gain optimal TDFA pumping schemes (see Table 1).

Table 1. Optimal TDFA parameters (maximum gain).

\begin{tabular}{cccc}
\hline $\begin{array}{c}\text { Pumping } \\
\text { scheme }\end{array}$ & $\begin{array}{c}\text { forward pump } \\
\text { wavelength, nm }\end{array}$ & $\begin{array}{c}\text { backward pump } \\
\text { wavelength, nm }\end{array}$ & $\begin{array}{c}\text { forward } \\
\text { pump ratio }\end{array}$ \\
\hline$a, b$ & 1028 & - & 1.00 \\
$c$ & 1400 & 1502 & 0.87 \\
$d$ & 833 & 1399 & 0.27 \\
$e$ & 773 & 1030 & 0.06 \\
\hline
\end{tabular}

Table 2. Optimal TDFA parameters (minimum gain ripple).

\begin{tabular}{cccc}
\hline $\begin{array}{c}\text { Pumping } \\
\text { scheme }\end{array}$ & $\begin{array}{c}\text { forward pump } \\
\text { wavelength, nm }\end{array}$ & $\begin{array}{c}\text { backward pump } \\
\text { wavelength, nm }\end{array}$ & $\begin{array}{c}\text { forward } \\
\text { pump ratio }\end{array}$ \\
\hline$a, b$ & 1028 & - & 1.00 \\
$c$ & 1398 & 1542 & 0.96 \\
$d$ & 770 & 1397 & 0.03 \\
$e$ & 775 & 1024 & 0.22 \\
\hline
\end{tabular}


optimization criteria three-step up-conversion pumping schemes (namely, $a$ and $e$ ) demonstrate the best results. Moreover, the additional pumping at $1560 \mathrm{~nm}$ in scheme $b$ deteriorates the amplifier performance only both maximal gain and minimal gain ripple are achieved by using single forward pump at $1028 \mathrm{~nm}$. Additionally, scheme $a$ is optimal in terms of noise figure (see Fig. 5), other schemes demonstrate substantially higher noise output. The difference between these results and those reported in [13] is attributed to the numerical method issue that is corrected in the current investigation.

As compared to conventional step-index fibre, $\mathrm{W}$-type fibre provides small performance improvement. According to our numerical experiments the usage of W-type fibre can increase maximal gain of TDFA for about $0.2 \mathrm{~dB}$ at best for optimized pump conditions.

\section{Conclusion}

Completely spectrally and spatially resolved theoretical TDFA model is presented and used for optimizing wavelengths and powers of bidirectional pumping for several up-conversion pumping schemes. The distinguishing feature of our model is taking into account the mode structure of emission in spectral range 400 $2200 \mathrm{~nm}$ characteristic of TDFA. Genetic algorithm method is used to find the optimal pumping parameters for attaining the maximum gain or minimum gain ripple of TDFA in 1450-1500 nm spectral band.

The obtained results show that the best pumping schemes for achieving the maximum gain or minimum gain ripple in the considered spectral range are the three-step up-conversion pumping schemes at wavelength near $1030 \mathrm{~nm}$ with or without additional pumping to the upper laser level. Additional pumping to the lower laser level makes performance of TDFA worse (it should be noted that the optimization was carried out at the constant value of total pump power). As the result of numerical experiments, the following parameter val- ues that characterize the performance of TDFA utilizing optimized for maximal gain up-conversion pumping scheme at $1028 \mathrm{~nm}$ are obtained: maximal gain $22.3 \mathrm{~dB}$, noise figure and gain unevenness in 1450$1490 \mathrm{~nm}$ band less than 7 and $10.3 \mathrm{~dB}$ respectively.

Utilizing the single-mode W-type fibre that is filtering long wavelength ASE can improve silica-host stepindex TDFA gain by $0.2 \mathrm{~dB}$ only.

\section{References}

[1] T. Komukai, T. Yamamoto, T. Sugawa, and Y. Miyajima, IEEE J. Quantum Electron. 31, 1880 (1995).

[2] T. Kasamatsu, Y. Yano, and T. Ono, Electron. Lett. 36, 1607 (2000).

[3] A.S.L. Gomes, M.T. Carvalho, M.L. Sundheimer, C.J.A. Bastos-Filho, J.F. Martins-Filho, J.P.V der Weid, and W. Margulis, Opt. Lett. 28, 334 (2003).

[4] F. Roy, D. Bayart, and P. Baniel, in: Optical Fiber Communication Conference, OSA Technical Digest Series (Optical Society of America, 2000), paper WA6.

[5] W.J. Lee, B. Min, J. Park, and N. Park, in: Optical Fiber Communication Conference, 2001 OSA Technical Digest Series (Optical Society of America, 2000), paper TuQ 5.

[6] P. Peterka, B. Faure, W. Blanc, M. Karasek, and B. Dussardier, Opt. Quantum Electron. 36, 201 (2004).

[7] S. Yoo, Y. Jung, J. Kim, J.W. Lee, and K. Oh, Opt. Fiber Technol. 11, 332 (2005).

[8] C. Kakkar, G. Monnom, K. Thyagarajan, and B. Dussardier, Opt. Commun. 262, 193 (2006).

[9] M. Monerie, J. Quantum Electron. 18, 535 (1982).

[10] E. Desurvire, Erbium-Doped Fiber Amplifiers: Principles and Applications (Wiley-Interscience, New York, 1994).

[11] J.H. Holland, Adaptation in Natural and Artificial Systems (The MIT Press, Massachusets, 1992).

[12] M. Mitchell, An Introduction to Genetic Algorithms (The MIT Press, Cambridge, MA, 1998).

[13] M.A. Khodasevich, S.A. Koval, and G.V. Sinitsyn, Opt. Spectrosc. 107, 388 (2009). 


\title{
SIGNALO STIPRINIMO IR TRIUKŠMŲ LYGIO SKAITMENINE் ANALIZĖ S JUOSTOS SU Tm PRIEMAIŠA W TIPO ŠVIESOLAIDINIAME STIPRINTUVE ESANT İVAIRIOMS KAUPINIMO KONFIGŪRACIJOMS
}

\author{
M.A. Khodasevich, S.A. Koval, G.V. Sinitsyn \\ Baltarusijos nacionalinès mokslu akademijos B.I. Stepanovo fizikos institutas, Minskas, Baltarusija
}

\section{Santrauka}

Pristatytas silicio oksido šerdies su tulio priemaišomis šviesolaidinio stiprintuvo teorinis modelis, visiškai atskiriantis spektrinius ir erdvinius parametrus. Palyginti su anksčiau siūlomais modeliais, pastarasis atsižvelgia ị daugiamodès spinduliuotès sandarą. Aptarta keletas perspektyvių kaupinimo schemų. Genetinis algoritmas pri- taikytas kaupinimo schemai optimizuoti siekiant maksimalaus stiprinimo arba minimalių stiprinimo pulsacijų. Palygintos $\mathrm{W}$ tipo ir laiptinio lūžio rodiklio šviesolaidžių eksploatacinès charakteristikos. Gauti rezultatai kiekvienai aptartai schemai leidžia parinkti geriausius parametrus. 